\title{
Low Efficacy of Isaria fumosorosea against Box Tree Moth Cydalima perspectalis: Are Host Plant Phytochemicals Involved in Herbivore Defence against Fungal Pathogens?
}

\author{
Rostislav Zemek ${ }^{1,2,3, * \mathbb{C} \text {, Jana Konopická }}{ }^{3,4}$ (i) and Zain Ul Abdin ${ }^{1,2,5}$ \\ 1 Arthropod Ecology and Biological Control Research Group, Ton Duc Thang University, \\ Ho Chi Minh City 758307, Vietnam; zainulabdin@tdtu.edu.vn \\ 2 Faculty of Applied Sciences, Ton Duc Thang University, Ho Chi Minh City 758307, Vietnam \\ 3 Biology Centre of the Czech Academy of Sciences, Institute of Entomology, 37005 České Budějovice, \\ Czech Republic; jkonopicka@seznam.cz \\ 4 Department of Plant Production, Faculty of Agriculture, University of South Bohemia, \\ 37005 České Budějovice, Czech Republic \\ 5 Department of Entomology, University of Agriculture, Faisalabad 38000, Pakistan \\ * Correspondence: rostislav.zemek@tdtu.edu.vn
}

Received: 16 November 2020; Accepted: 3 December 2020; Published: 6 December 2020

\begin{abstract}
Buxus sp. is an important native and ornamental tree in Europe threatened by a serious invasive pest Cydalima perspectalis. The larvae of this moth are able to defoliate box trees and cause their death. The development of novel biopesticides targeting this pest might help protect Buxus trees grown wildly or in city parks. Laboratory experiments were conducted to assess the efficacy of entomopathogenic fungus Isaria fumosorosea strain CCM 8367 against C. perspectalis. The last-instar larvae of the box tree moth were treated by the suspension of fungus conidia at concentrations ranging from $1 \times 10^{4}$ to $1 \times 10^{8}$ spores per $1 \mathrm{~mL}$. Fungus infection was observed mostly in pupae, but the maximum mortality did not exceed $60 \%$, indicating a very low susceptibility of $C$. perspectalis to I. fumosorosea. Furthermore, a number of ungerminated fungal conidia were found on larval cuticles using a low-temperature scanning electron microscopy. Our data also reveal that the hydroalcoholic extract from $B$. sempervirens leaves significantly inhibits both the germination of $I$. fumosorosea conidia and fungus growth. It can be speculated that the strain CCM 8367 of I. fumosorosea is not a potent biocontrol agent against $C$. perspectalis and low virulence of the fungus might be due to the accumulation of host plant phytochemicals having antimicrobial activity in larval cuticle of the pest.
\end{abstract}

Keywords: Buxus; entomopathogenic fungi; invasive pests; virulence; alkaloids; antimicrobial activity

\section{Introduction}

Box trees, Buxus sp., are important evergreen shrubs occurring in natural Buxus forests [1] or grown as ornamental trees in city parks in Europe. They are now endangered by the box tree moth (BTM), Cydalima perspectalis (Walker) (Lepidoptera: Crambidae), which is a serious invasive pest native to Asia that was first detected in Germany in 2007 and has since invaded a large area causing significant damage [2,3]. This pest overwinters at the larval stage [4,5] and can have two to four generations per year in Europe depending on abiotic conditions [6]. Natural enemies do not suppress the $C$. perspectalis population, which is probably because this exotic species does not seem to be a good host for native parasitoids $[4,7,8]$. Thus, the pest is able to destroy Buxus tree completely in one season [9]. Some synthetic chemical insecticides are effective in C. perspectalis control [10]. Still, 
their application in natural habitats is problematic because of their adverse side effects on non-target species. Their frequent application possibly leads to the risk of resistance development in the pest.

The use of microbial biopesticides against BTM offers a unique alternate solution to broad-spectrum chemical insecticides. The best results have been obtained by using products based on Bacillus thuringiensis Berliner (Bacillales: Bacillaceae) while entomopathogenic nematode Steinernema carpocapsae (Weiser) (Rhabditida: Steinernematidae) was less successful [11]. Entomopathogenic fungi (EPFs) represent other promising biocontrol agents. Their advantages are that they do need to be ingested as they are able to penetrate the host cuticle and can be relatively easily produced [12]. A number of mycoinsecticides, most commonly based on Beauveria bassiana (Balsamo) Vuillemin (Hypocreales: Cordycipitaceae), Metarhizium anisopliae (Metsch.) Sorokin, (Hypocreales: Clavicipitaceae), Isaria fumosorosea (WIZE) Brown \& Smith (Hypocreales: Cordycipitaceae), and B. brongniartii (Saccardo) (Hypocreales: Cordycipitaceae) have been developed in the world [13]. To our knowledge, only B. bassiana strain GY1-17 was tested against BTM in Korea, but larvae were not affected significantly [14].

The present study aimed to assess the possibility of fungal biocontrol of $C$. perspectalis by I. fumosorosea, which is known to be virulent to many insect species including a wide variety of butterflies and moths [15-17] and has received significant attention as a possible biological control agent for several economically important pests [18]. The obtained results showed low efficacy of the fungus against this pest. Therefore, additional experiments were conducted to test the hypothesis that the low effectiveness might be due to the antifungal activity of some host plant phytochemicals consumed by the moth larvae. Low-temperature scanning electron microscopy revealed that the number of I. fumosorosea conidia did not germinate. In vitro experiments confirmed that the hydroalcoholic extract of Buxus leaves suppressed spore germination and fungus growth.

\section{Materials and Methods}

\subsection{Insects}

Last-instar larvae of $C$. perspectalis were collected from unsprayed Buxus sempervirens trees located in a private garden in Staré Hodějovice (South Bohemia, Czech Republic, $49^{\circ} \mathrm{N}$ ) and maintained in net cages at a room temperature with 16L:8D photoperiod for a few days before they were used in bioassays. Young twigs of untreated box trees collected in the vicinity of the Biology Centre, České Budějovice were provided as food and replaced with fresh ones when needed.

\subsection{Entomopathogenic Fungus}

Isaria fumosorosea strain CCM 8367 was used in this study. The strain was isolated from the pupa of the horse chestnut leaf miner, Cameraria ohridella, Deschka \& Dimić (Lepidoptera: Gracillariidae) collected in the Czech Republic [19] and deposited in the Czech Collection of Microorganisms in Brno as a patent culture [20,21].

The fungus was grown on PDA medium (Sigma-Aldrich, Darmstadt, Germany) at $25 \pm 1{ }^{\circ} \mathrm{C}$ and a 16L:8D photoperiod. After 10 days of incubation, the spore suspensions were prepared from each strain by scraping off conidia into the sterile solution of $0.05 \%(v / v)$ Tween ${ }^{\circledR} 80$ (Sigma-Aldrich, Darmstadt, Germany). The suspension was filtered through sterile gauze to separate the mycelium and clusters of spores. In uniform suspension, the spores were counted with a Neubauer improved counting chamber (Sigma-Aldrich, Darmstadt, Germany), and subsequently, the suspension was adjusted to the required concentration.

The viability of spores was verified using a standard germination test [22]. Ten drops from suspension were applied using a $1 \mu \mathrm{L}$ inoculation loop on the surface of $2 \%$ water agar, which was poured in a thin layer onto the surface of a sterile slide. After the drops had dried, the slides were moved into a wet chamber and incubated at temperature $25 \pm 1{ }^{\circ} \mathrm{C}$ for $24 \mathrm{~h}$. The percentage of germinating spores was determined using an Olympus CH20 light microscope (Olympus Optical Co., Ltd., Tokyo, Japan); bright field, $400 \times$ magnification. The spore germination in all tests was $100 \%$. 


\subsection{Bioassays}

\subsubsection{The Efficacy of I. fumosorosea against C. perspectalis}

Five concentrations of $I$. fumosorosea ranging from $1 \times 10^{4}$ to $1 \times 10^{8}$ spores per $1 \mathrm{~mL}$ were used in this experiment. The last-instar larvae of BTM in treated groups were individually immersed in the suspension of conidiospores of the fungus for five seconds (dip-test). All specimens in a control group were immersed in sterile solution of $0.05 \%$ Tween ${ }^{\circledR} 80$ only. Then, the larvae were placed into polystyrene Petri dishes (vented, inner diameter $90 \mathrm{~mm}$, height $15 \mathrm{~mm}$, Gosselin ${ }^{\mathrm{TM}}$, Borre, France) lined with moist filter paper (KA 0, Papírna Perštejn, Ltd., Perštejn, Czech Republic) and kept under constant conditions ( $25 \pm 1{ }^{\circ} \mathrm{C}$ and 16L:8D photoperiod). Larvae were fed with B. sempervirens leaves, which were replaced daily until larva developed into pupa or died. The filter paper was also daily moistened by distilled water to maintain optimal humidity inside the Petri dishes. The insects were monitored daily for a period of three weeks to record insect development, mortality, and the development of mycosis on cadavers until all individuals died or adults emerged.

All bioassays described above were repeated twice; each replication tested 15 insect individuals. Mycosis on cadavers and emerged adults were documented by digital cameras Olympus SP-510 (Olympus Optical Co., Ltd., Tokyo, Japan) and Nikon Coolpix 4500 (Nikon Corporation, Tokyo, Japan) mounted on a tripod and using macro mode.

\subsubsection{Scanning Electron Miscroscopy of I. fumosorosea Conidia Germination on Cuticle of C. perspectalis Larvae}

In vivo germination of fungal conidia on the insect cuticle was examined by low-temperature scanning electron microscopy (LT-SEM). BTM larvae were treated by immersing in suspension of I. fumosorosea conidia (concentration $5 \times 10^{7}$ spores $\mathrm{mL}^{-1}$ ) and incubated for 0,24 , and $48 \mathrm{~h}$ at the temperature of $25^{\circ} \mathrm{C}$. The larvae were mounted on an aluminum stub using Tissue-Tek (C.C.T.D. Compound, The Netherlands). The samples were extremely fast $\left(<10^{-3} \mathrm{~K} / \mathrm{s}\right)$ frozen in vapor of liquid nitrogen. After freezing, the samples were transfered into a GATAN ALTO-2500 high vacuum cryo-preparation chamber (Gatan Inc., Abingdon, UK). The surface of the sample was sublimated (freeze-etched) for $5 \mathrm{~min}$ at the temperature of $-95^{\circ} \mathrm{C}$ and at $-130{ }^{\circ} \mathrm{C}$. After sublimation, the samples were sputter-coated with gold at the temperature of $-130^{\circ} \mathrm{C}$. Coated samples were inserted into the chamber of a JEOL JSM-7401F Field Emission Scanning Electron Microscope (JEOL Ltd., Tokyo, Japan). Images were obtained by the secondary electron signal at an accelerating voltage of $4 \mathrm{kV}$ and current $10 \mu \mathrm{A}$ using an Everhart-Thornley Detector (ETD).

\subsubsection{The Effect of $B$. sempervirens Extract on I. fumosorosea Germination and Growth}

Plant material was collected from untreated B. sempervirens trees grown in the Biology Centre garden. The extract used for the study was prepared at the concentration of $20 \%(w / v)$ by grinding $2 \mathrm{~g}$ of fresh leaves in $10 \mathrm{~mL}$ of solvent (water-ethanol 1:1 mixture). Analytic grade ethanol (Penta Ltd., Czech Republic) and distilled water were used. The mixture was filtered through filter paper (KA 0, Papírna Perštejn, Ltd., Czech Republic) to remove particulate materials, and one milliliter of fresh extract was spread on the surface of $2 \%$ water agar in Petri dish and left to dry for $24 \mathrm{~h}$. Then, a suspension of I. fumosorosea conidia was applied using an inoculation loop on the surface. Germination was evaluated in 100 spores after $24 \mathrm{~h}$ of incubation at $25 \pm 1{ }^{\circ} \mathrm{C}$ as described above. The control plate was treated with solvent only. The experiment was conducted in three replicates. Spore germination was documented by NIS-Elements Imaging Software and a Nikon Eclipse E200 microscope equipped with Nikon DS-Fi3 color camera (Nikon Corporation, Tokyo, Japan).

The effect $B$. sempervirens extract on fungus growth was measured by a modified inhibition zone

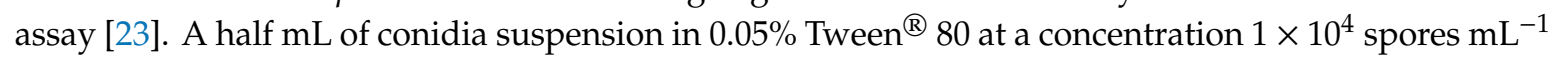
was spread evenly on potato dextrose agar (PDA) medium in a plastic Petri dish (diameter $90 \mathrm{~mm}$ ). A hydroalcoholic extract of $B$. sempervirens leaves prepared as described above was applied on filter 
paper discs (diameter $14 \mathrm{~mm}$ ) in a dose $150 \mu \mathrm{L}$ per disc. Control discs were treated with $150 \mu \mathrm{L}$ of the pure solvent. The solvent was allowed to evaporate, and paper discs were placed carefully in the center of PDA plates. After 7 days incubation at $25^{\circ} \mathrm{C}$, the plates were photographed by a digital camera Olympus SP-510 (Olympus Optical Co., Ltd., Tokyo, Japan) mounted on a tripod to document differences in fungus growth. Then, the area of plate in the center not covered by I. fumosorosea mycelium was measured using ImageJ, a Java-based image analysis software [24]. The assay was conducted using 10 dishes (replications) for both treatment and control.

\subsection{Data Analysis}

To analyze the effect of treatment on developmental time of $C$. perspectalis larvae and pupae, we fitted generalized linear models (GLM) with a Poisson error distribution and log link function. Mortality as well as germination data were analyzed using GLM with a binomial distribution and logit link. Treatment and replication were set as fixed effects. The analyses were performed in SAS ${ }^{\circledR}$ Studio for Linux [25] using the GLM procedure (PROC GENMOD) of SAS/STAT ${ }^{\circledR}$ module [26]. Means were separated by the least-square means (LSMEANS) statement of SAS with Tukey-Kramer adjustment for multiple comparisons. $p$-values $<0.05$ were considered statistically significant. Lethal concentrations $\left(\mathrm{LC}_{50}\right.$ and $\mathrm{LC}_{90}$ ) were estimated using Probit analysis (PROC PROBIT). Differences in area not covered by I. fumosorosea mycelium were compared by an exact Wilcoxon two-sample test (PROC NPAR1WAY) of the SAS/STAT ${ }^{\circledR}$ module.

\section{Results and Discussion}

Most BTM larvae successfully passed to pupa regardless of treatment (Table 1), and no statistically significant effect of treatment on the duration of the larval stage was observed $\left(\chi^{2}=10.08, \mathrm{df}=5\right.$, $p=0.0730)$. Similarly, treatments had no significant effect on the duration of the pupal stage $\left(\chi^{2}=0.19\right.$, $\mathrm{df}=5, p=0.9992)$, but higher mortality was observed in all treatments; the maximum mortality of $46.4 \%$ pupae was found with the highest concentration of fungal treatment.

Table 1. The effects of Isaria fumosorosea on the development of Cydalima perspectalis.

\begin{tabular}{|c|c|c|c|c|c|c|c|}
\hline \multirow{3}{*}{ Treatment $^{1}$} & \multicolumn{3}{|c|}{ Last-Instar Larvae } & \multicolumn{3}{|c|}{ Pupae } & \multirow{3}{*}{$\begin{array}{c}\text { Malformed } \\
\text { Adults } \\
\% \%\end{array}$} \\
\hline & \multicolumn{2}{|c|}{ Duration } & \multirow{2}{*}{$\begin{array}{c}\text { Died/Mycosed } \\
\%\end{array}$} & \multicolumn{2}{|c|}{ Duration } & \multirow{2}{*}{$\begin{array}{c}\text { Died/Mycosed } \\
\%\end{array}$} & \\
\hline & Mean \pm SE & $n$ & & Mean \pm SE & $n$ & & \\
\hline Control & $4.24 \pm 0.41$ & 29 & $3.3 / 0$ & $10.10 \pm 0.15$ & 21 & $27.6 / 0$ & 0 \\
\hline $1 \times 10^{4}$ & $5.04 \pm 0.58$ & 28 & $6.7 / 0$ & $10.33 \pm 0.11$ & 18 & $35.7 / 0$ & 0 \\
\hline $1 \times 10^{5}$ & $5.53 \pm 0.54$ & 30 & $0 / 0$ & $10.17 \pm 0.13$ & 24 & $20.0 / 0$ & 0 \\
\hline $1 \times 10^{6}$ & $4.87 \pm 0.43$ & 30 & $0 / 0$ & $10.46 \pm 0.10$ & 26 & $13.3 / 0$ & 0 \\
\hline $1 \times 10^{7}$ & $5.00 \pm 0.31$ & 30 & $0 / 0$ & $10.33 \pm 0.11$ & 21 & $30.0 / 10.0$ & 0 \\
\hline $1 \times 10^{8}$ & $3.96 \pm 0.32$ & 28 & $6.7 / 3.3$ & $10.27 \pm 0.25$ & 15 & $46.4 / 28.6$ & 20.0 \\
\hline
\end{tabular}

Mycosis was observed only in treatments of $1 \times 10^{7}$ and $1 \times 10^{8}$ conidia per $1 \mathrm{~mL}$ when $10 \%$ and $28.6 \%$ of pupae cadavers, respectively, were obviously infected by the fungus (Table 1 ). Infection by I. fumosorosea was later confirmed when fungus sporulated (Figure 1).

Interestingly, several adults that emerged from larvae treated by the highest conidia concentration were malformed (Table 1, Figure 2) and died in 1-2 days. A similar effect was observed when I. fumosorosea was applied to Spodoptera littoralis (Boisd.) [27]. 


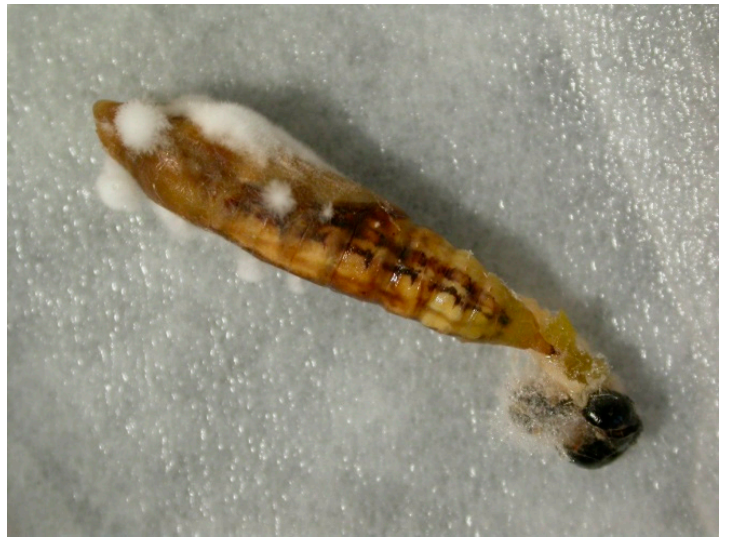

(a)

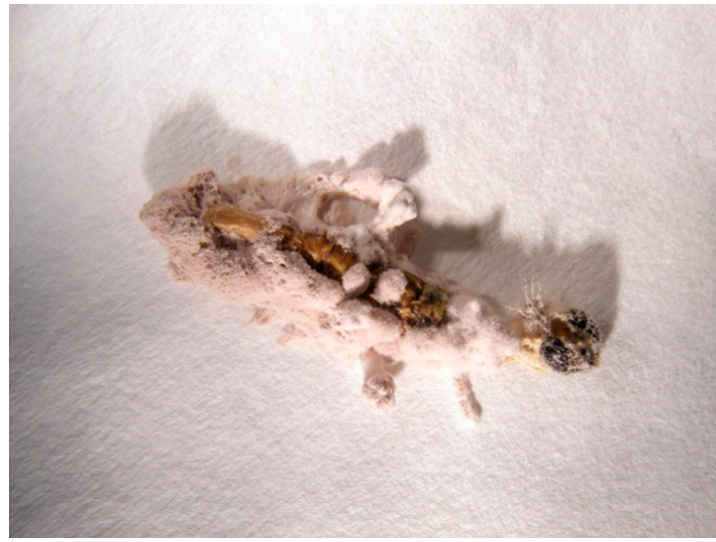

(b)

Figure 1. (a) Early mycosis of Isaria fumosorosea on Cydalima perspectalis pupa; (b) Cadaver of C. perspectalis covered with sporulating fungus.

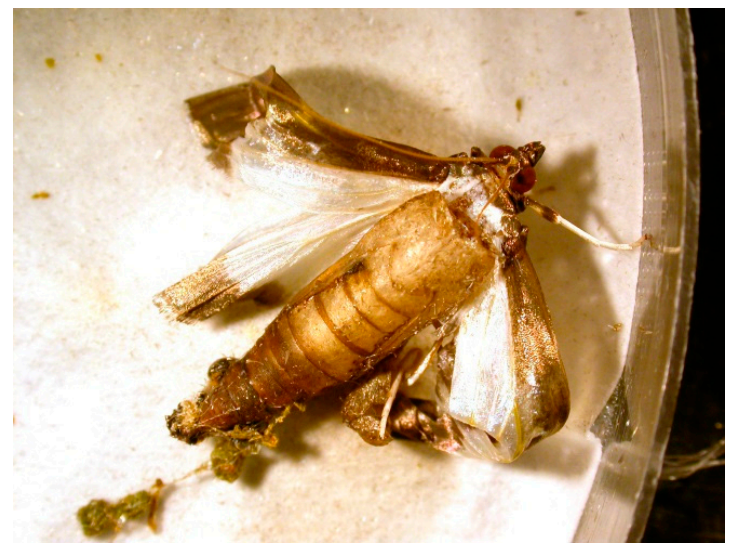

(a)

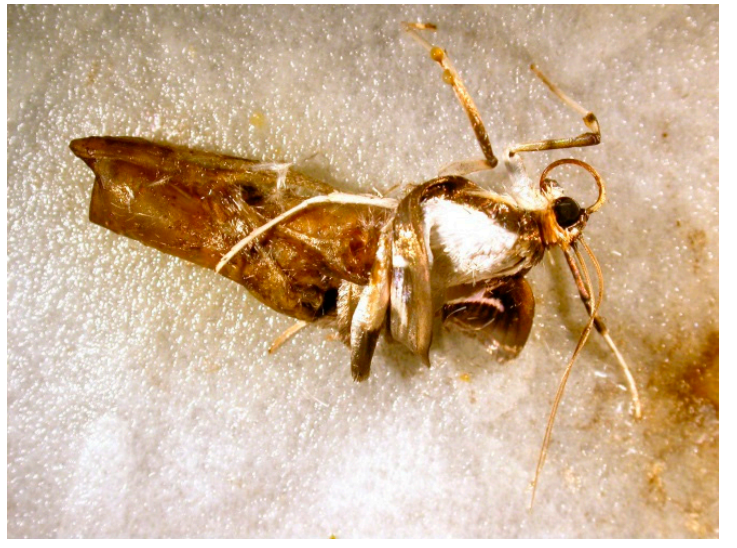

(b)

Figure 2. (a,b) Malformed adults of Cydalima perspectalis emerged in a group of larvae treated by Isaria fumosorosea at a concentration $1 \times 10^{8}$ conidia $/ \mathrm{mL}$.

The cumulative mean mortality, including mortality in malformed adults, varied among treatments and reached a maximum value of $60 \%$ when larvae were treated by a suspension of $1 \times 10^{8}$ conidia per $1 \mathrm{~mL}$ (Figure 3a). Thus, the highest mortality corrected for mortality in the control group [28] was only $42.9 \%$. Although the effect of treatment on mortality was significant $\left(\chi^{2}=18.67, \mathrm{df}=5, p=0.0022\right)$ and no significant differences were found between replications $\left(\chi^{2}=0.45, \mathrm{df}=1, p=0.5004\right)$, the results indicate the very low susceptibility of $C$. perspectalis to I. fumosorosea.

The low efficacy is rather surprising, because the strain CCM 8367 of I. fumosorosea used in this study was previously found to be highly virulent against several pest species. For example, the mortality of pupae of C. ohridella, an invasive pest of Aesculus hippocastanum in Europe [29], treated by blastospores or conidia suspension of concentration $5 \times 10^{7}$ spores per $1 \mathrm{~mL}$ reached $100 \%$ over a few days [20]. Later, the high efficacy of this strain was confirmed against Spodoptera littoralis (Boisd.) in which an application of CCM 8367 blastospores at a concentration of $5 \times 10^{7}$ per $1 \mathrm{~mL}$ caused larval mortality $>90 \%$ [27]. The high efficacy of CCM 8367 under laboratory conditions similar to that used in the present study was reported also against Colorado potato beetle, Leptinotarsa decemlineata, (Say) (Coleoptera: Chrysomelidae) larvae [30]. This indicated that the strain could be a prospective biocontrol agent, although some side effects against non-target natural enemies were also reported [31]. 


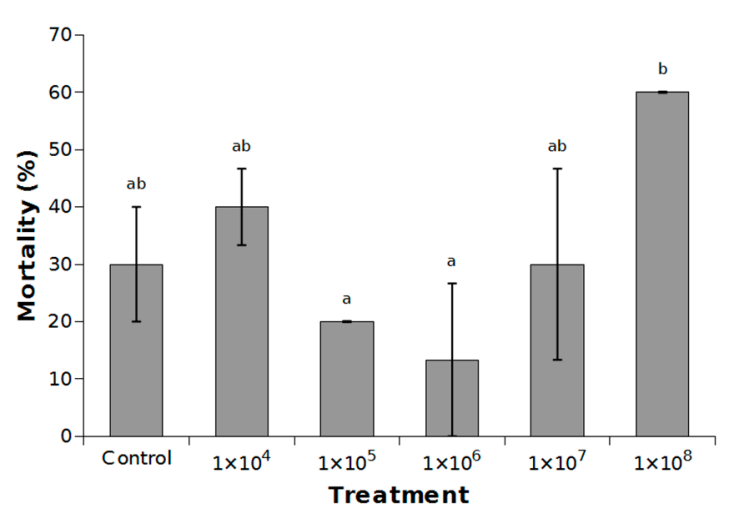

(a)

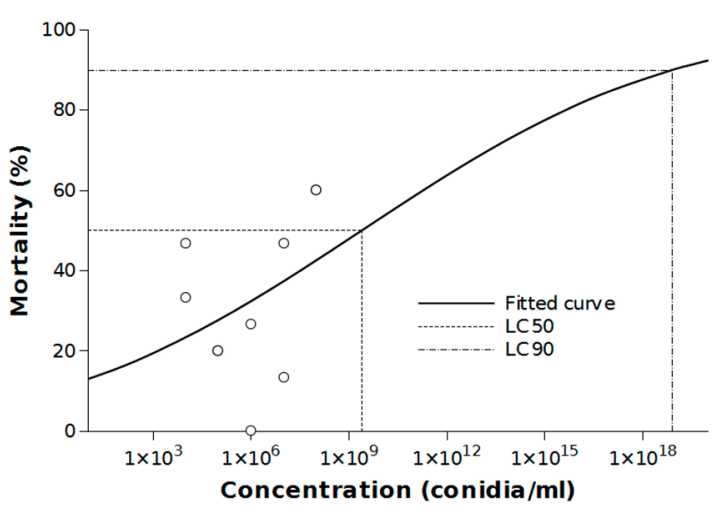

(b)

Figure 3. (a) Mean cumulative mortality $( \pm \mathrm{SE})$ of Cydalima perspectalis (including mortality of malformed adults) treated with various concentrations of Isaria fumosorosea conidia. A generalized linear model was fitted and pairwise between treatment differences were tested using the least-square means. Different letters indicate significant differences between columns $(p<0.05)$; (b) Log-probit regression line of concentration-mortality response of $C$. perspectalis to I. fumosorosea.

The log-probit regression line describing the relationship between concentration and mortality has a form $y=-1.264+0.135 x$ (Figure $3 b$ ), but the slope was not statistically significant $\left(\chi^{2}=3.27\right.$, $\mathrm{df}=1, p=0.071)$. Thus, the extrapolated values of $\mathrm{LC}_{50}=2.42 \times 10^{9}$ and $\mathrm{LC}_{90}=7.88 \times 10^{18}$ were very high. For example, this contrasts with the $\mathrm{LC}_{50}$ and $\mathrm{LC}_{90}$ values of $1.03 \times 10^{6}$ and $8.67 \times 10^{7}$, respectively, reported for L. decemlineata [30].

LT-SEM imaging of I. fumosorosea conidia on the cuticle of BTM larvae revealed a high number of spores immediately after treatment (Figure $4 \mathrm{a}, \mathrm{b}$ ), but after 24 and $48 \mathrm{~h}$ of incubation, the number of attached spores seemed to be much lower, as we found them only in some places of larvae, usually as small groups or individual conidia. This indicates low conidial attachment to the larvae cuticle. Examination further showed that the number of spores did not germinate (Figure $4 \mathrm{~d}-\mathrm{f}$ ). This finding might explain the low virulence of the fungus against $C$. perspectalis because the successful germination of fungus conidia on the host cuticle has been considered to be necessary for infection [32,33]. Several studies documented that the cuticle of some arthropods repress the germination of EPF spores or further development of germlings and appressoria formation $[34,35]$. One of the reasons might be the presence of antifungal compounds on the cuticle [36,37], which might be also case of $C$. perspectalis.

Results of in vitro experiments using B. sempervirens hydro-alcoholic extract revealed that this extract has a negative effect on the germination of I. fumosorosea conidia (Figure 5). In the control treated by solvent, the mean germination was $100 \%(\mathrm{SE}=0, n=3)$, while on extract-treated agar, the mean germination was only $92.67 \%(\mathrm{SE}=0.88, n=3)$ in average. The difference was statistically highly significant $\left(\chi^{2}=31.36, \mathrm{df}=1, p<0.0001\right)$.

The inhibition zone assay showed the suppression of I. fumosorosea mycelium growth on filter paper discs treated by B. sempervirens extract. The mean area not covered by mycelium was $0.02 \pm 0.01 \mathrm{~mm}^{2}$ and $53.83 \pm 19.86 \mathrm{~mm}^{2}$ in control and treated discs, respectively. The differences were statistically significant $(Z=-2.184, p=0.028)$.

Our findings indicate the presence of phytochemicals in box tree leaves having some activity against entomopathogenic fungi. Several secondary plant compounds were found to have a negative effect on the germination of I. fumosorosea blastospores, indicating that the presence of allelochemicals on a substrate (e.g., insect cuticle or leaf) may be an additional constraint to the survival of entomopathogenic fungi [38]. The Buxus trees contain a lot of alkaloids, some of which are sequestered by C. perspectalis larvae, while some are metabolized and/or excreted [39]. The antimicrobial activity of substances extracted from B. sempervirens by $65 \%$ ethanol were found earlier [40], and similar effects of box tree extracts were confirmed by other authors [41]. Thus, it is thus likely that BTM larvae use 
phytochemicals obtained from the host plant for their own defense against the invasion of microbial pathogens. This might explain the low efficacy of two strains of entomopathogenic fungi, I. fumosorosea (present study), and B. bassiana [14] against BTM.

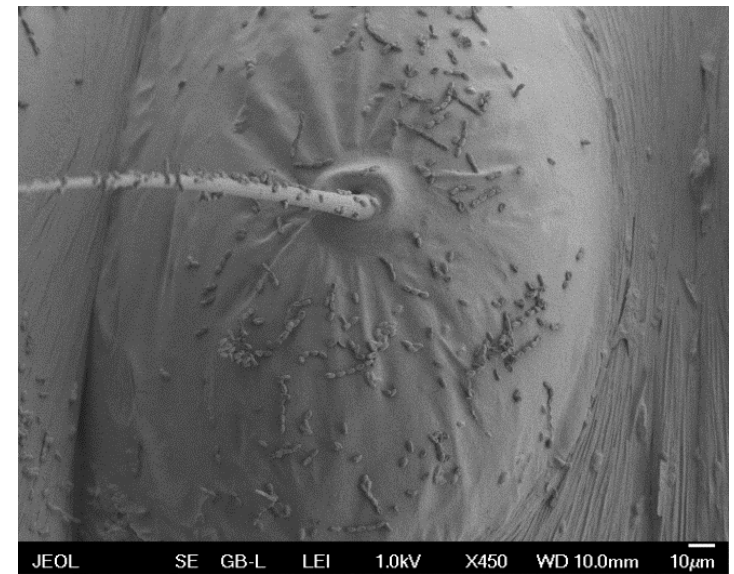

(a)

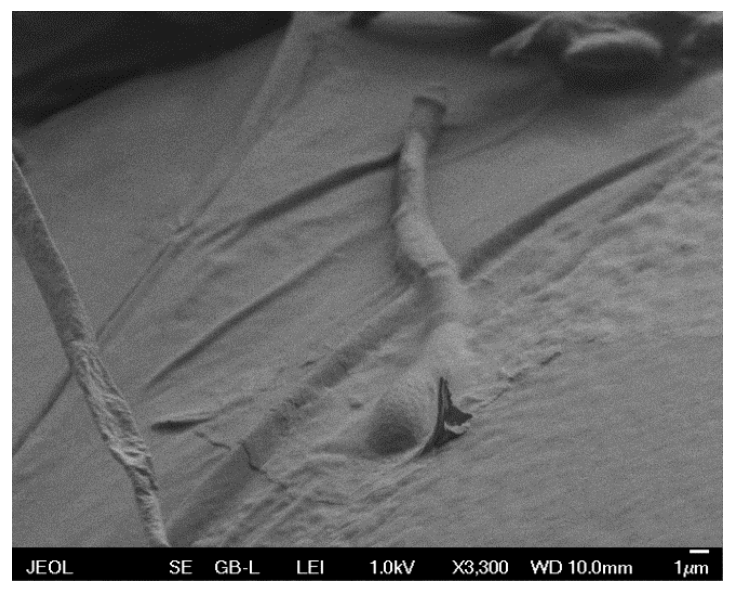

(c)

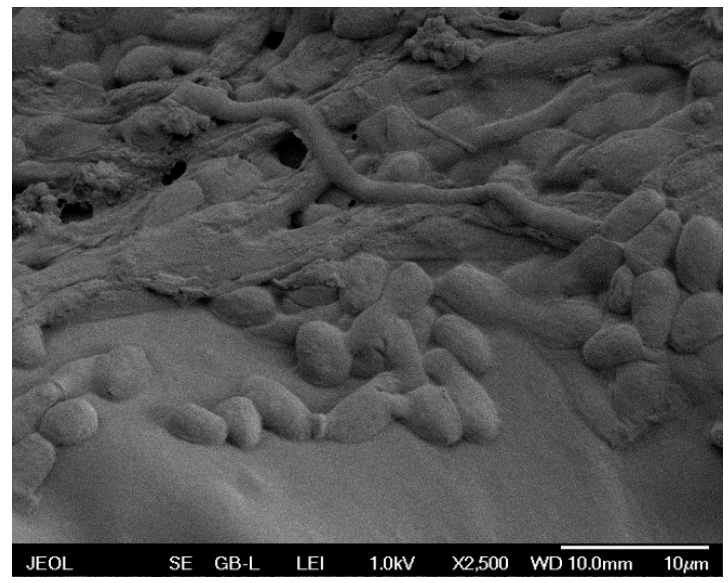

(e)

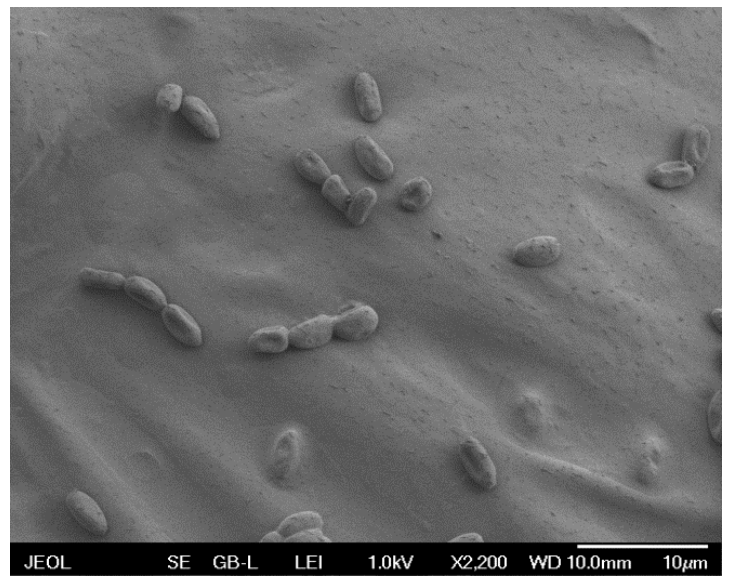

(b)

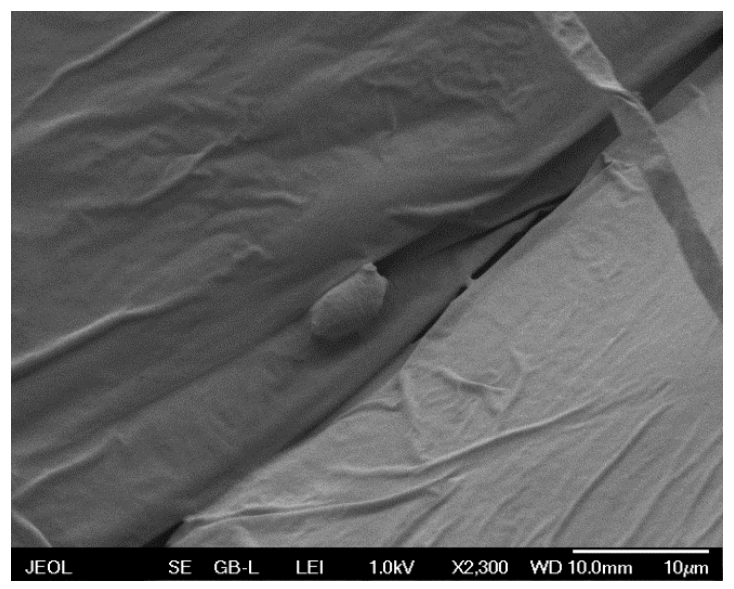

(d)

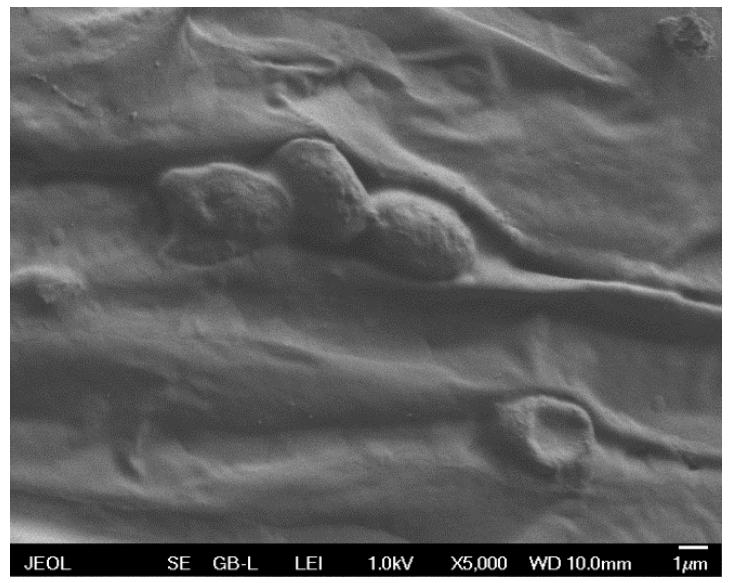

(f)

Figure 4. Low-temperature scanning electron microscope (LT-SEM) image of Isaria fumosorosea conidia on the cuticle of Cydalima perspectalis larva. $(\mathbf{a}, \mathbf{b})$ Conidia immediately after the fungus application; (c) Conidium with germ tube after 24-h incubation; (d) Ungerminated conidium after 24-h incubation; (e) Group of ungerminated conidia after 24-h incubation; (f) Ungerminated conidia after 48-h incubation. 


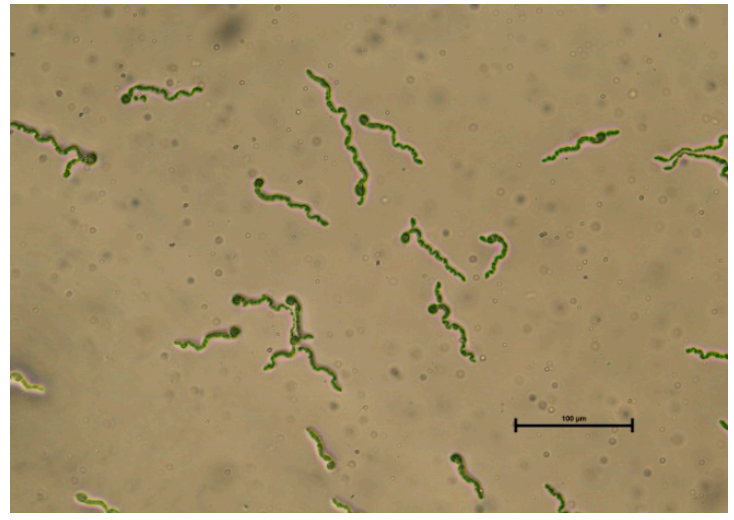

(a)

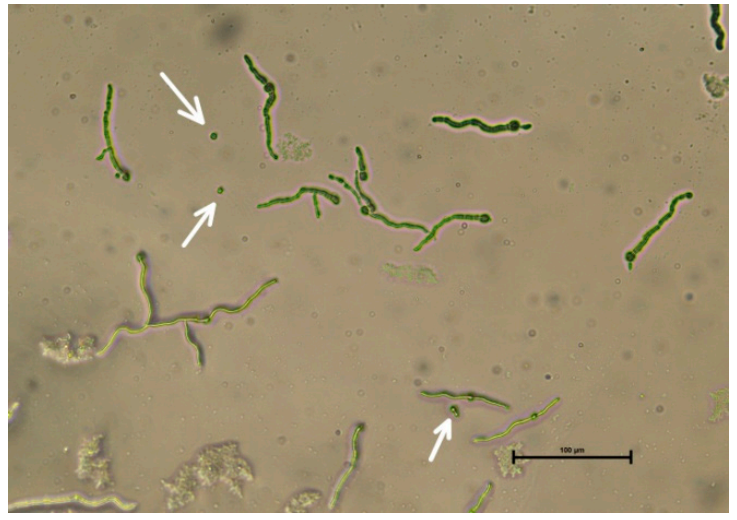

(b)

Figure 5. Germination of Isaria fumosorosea conidia on: (a) a control agar plate treated with solvent only; (b) agar plate treated with Buxus sempervirens extract. Arrows indicate spores with no or little germination peg. Traces of plant extract are visible on the agar surface.

It may be concluded that the strain CCM 8367 of I. fumosorosea is not a potent biocontrol agent against $C$. perspectalis and that the reason for the low efficacy of the fungus might be the accumulation of host plant phytochemicals with antimicrobial activity in the fifth-instar larvae cuticle of the pest.

Author Contributions: Conceptualization, R.Z.; methodology, R.Z. and J.K.; conducting experiments, R.Z. and J.K.; data analysis, R.Z.; writing-original draft preparation, R.Z.; writing-review and editing, R.Z., J.K. and Z.U.A.; supervision, R.Z.; project administration, Z.U.A.; funding acquisition, Z.U.A. and R.Z. All authors have read and agreed to the published version of the manuscript.

Funding: This research is funded by the Foundation for Science and Technology Development of Ton Duc Thang University (FOSTECT), website: http://fostect.tdt.edu.vn, under Grant FOSTECT.2018.12.

Acknowledgments: We acknowledge the core facility Laboratory of Electron Microscopy, Biology Centre CAS supported by the MEYS CR (LM2018129 Czech-BioImaging) and ERDF (No. CZ.02.1.01/0.0/0.0/16_013/0001775). The authors thank Jiří Vaněček and Martina Tesařová for their valuable help with SEM imaging.

Conflicts of Interest: The authors declare no conflict of interest. The funders had no role in the design of the study; in the collection, analyses, or interpretation of data; in the writing of the manuscript, or in the decision to publish the results.

\section{References}

1. Di Domenico, F.; Lucchese, F.; Magri, D. Buxus in Europe: Late Quaternary dynamics and modern vulnerability. Perspect. Plant Ecol. Evol. Syst. 2012, 14, 354-362. [CrossRef]

2. Mitchell, R.; Chitanava, S.; Dbar, R.; Kramarets, V.; Lehtijärvi, A.; Matchutadze, I.; Mamadashvili, G.; Matsiakh, I.; Nacambo, S.; Papazova-Anakieva, I.; et al. Identifying the ecological and societal consequences of a decline in Buxus forests in Europe and the Caucasus. Biol. Invasions 2018, 20, 3605-3620. [CrossRef]

3. Bras, A.; Avtzis, D.N.; Kenis, M.; Li, H.; Vétek, G.; Bernard, A.; Courtin, C.; Rousselet, J.; Roques, A.; Auger-Rozenberg, M.-A. A complex invasion story underlies the fast spread of the invasive box tree moth (Cydalima perspectalis) across Europe. J. Pest Sci. 2019, 92, 1187-1202. [CrossRef]

4. Wan, H.; Haye, T.; Kenis, M.; Nacambo, S.; Xu, H.; Zhang, F.; Li, H. Biology and natural enemies of Cydalima perspectalis in Asia: Is there biological control potential in Europe? J. Appl. Entomol. 2014, 138, 715-722. [CrossRef]

5. Nacambo, S.; Leuthardt, F.L.G.; Wan, H.; Li, H.; Haye, T.; Baur, B.; Weiss, R.M.; Kenis, M. Development characteristics of the box-tree moth Cydalima perspectalis and its potential distribution in Europe. J. Appl. Entomol. 2014, 138, 14-26. [CrossRef]

6. Suppo, C.; Bras, A.; Robinet, C. A temperature- and photoperiod-driven model reveals complex temporal population dynamics of the invasive box tree moth in Europe. Ecol. Model. 2020, 432, 109229. [CrossRef] 
7. Göttig, S.; Herz, A. Are egg parasitoids of the genus Trichogramma (Hymenoptera: Trichogrammatidae) promising biological control agents for regulating the invasive Box tree pyralid, Cydalima perspectalis (Lepidoptera: Crambidae)? Biocontrol Sci. Technol. 2016, 26, 1471-1488. [CrossRef]

8. Martini, A.; Di Vitantonio, C.; Dindo, M.L. Acceptance and suitability of the box tree moth Cydalima perspectalis as host for the tachinid parasitoid Exorista larvarum. Bull. Insectol. 2019, 72, 150-160.

9. Alkan Akncı, H.; Kurdoğlu, O. Damage level of Cydalima perspectalis (Lepidoptera: Crambidae) on naturally growing and ornamental box populations in Artvin, Turkey. Kastamonu Üniversitesi Orman Fakültesi Derg. 2019. [CrossRef]

10. Fora, C.G.; Sasu, L.; Poşta, D.; Berac, C. Chemical possibilities of Cydalima perspectalis Walk. (Lepidoptera: Crambidae) control. J. Hortic. For. Biotechnol. 2016, 20, 31-34.

11. Göttig, S.; Herz, A. Susceptibility of the Box tree pyralid Cydalima perspectalis Walker (Lepidoptera: Crambidae) to potential biological control agents Neem (NeemAzal@-T/S) and entomopathogenic nematodes (Nemastar@) assessed in laboratory bioassays and field trials. J. Plant Dis. Prot. 2018, 125, 365-375. [CrossRef]

12. Shahid, A.; Rao, Q.; Bakhsh, A.; Husnain, T. Entomopathogenic fungi as biological controllers: New insights into their virulence and pathogenicity. Arch. Biol. Sci. 2012, 64, 21-42. [CrossRef]

13. de Faria, M.R.; Wraight, S.P. Mycoinsecticides and mycoacaricides: A comprehensive list with worldwide coverage and international classification of formulation types. Biol. Control 2007, 43, 237-256. [CrossRef]

14. SangMyeong, L.; DongWoon, L.; HoYul, C.; JiWoong, P. Pathogenicities of Beauveria bassiana GY1-17 against some agro-forest insect pests. Korean J. Appl. Entomol. 1997, 36, 351-356.

15. Smith, P. Control of Bemisia tabaci and the potential of Paecilomyces fumosoroseus as a biopesticide. Biocontrol News Inf. 1993, 14, 71N-78N.

16. Dunlap, C.A.; Jackson, M.A.; Wright, M.S. A foam formulation of Palecilomyces fumosoroseus, an entomopathogenic biocontrol agent. Biocontrol Sci. Technol. 2007, 17, 513-523. [CrossRef]

17. Hoy, M.A.; Singh, R.; Rogers, M.E. Evaluations of a novel isolate of Isaria fumosorosea for control of the asian citrus psyllid, Diaphorina citri (Hemiptera: Psyllidae). Fla. Entomol. 2010, 93, 24-32. [CrossRef]

18. Kim, J.S.; Je, Y.H.; Roh, J.Y. Production of thermotolerant entomopathogenic Isaria fumosorosea SFP-198 conidia in corn-corn oil mixture. J. Ind. Microbiol. Biotechnol. 2010, 37, 419-423. [CrossRef]

19. Zemek, R.; Prenerova, E.; Weyda, F. The first record of entomopathogenic fungus Paecilomyces fumosoroseus (Deuteromycota: Hyphomycetes) on the hibernating pupae of Cameraria ohridella (Lepidoptera: Gracillariidae). Entomol. Res. 2007, 37, A135-A136.

20. Prenerova, E.; Zemek, R.; Volter, L.; Weyda, F. Strain of Entomopathogenic Fungus Isaria fumosorosea CCM 8367 (CCEFO.011.PFR) and the Method for Controlling Insect and Mite Pests. U.S. Patent No. US 08574566, 5 November 2013.

21. Prenerova, E.; Zemek, R.; Volter, L.; Weyda, F. Strain of Entomopathogenic Fungus Isaria fumosorosea CCM 8367 (CCEFO.011.PFR) and the Method for Controlling Insect and Mite Pests. EPO Patent No. EP2313488, 29 April 2015.

22. Skalický, A.; Bohatá, A.; Šimková, J.; Osborne, L.S.; Landa, Z. Selection of indigenous isolates of entomopathogenic soil fungus Metarhizium anisopliae under laboratory conditions. Folia Microbiol. 2014, 59, 269-276. [CrossRef]

23. Ruther, J.; Podsiadlowski, L.; Hilker, M. Quinones in cockchafers: Additional function of a sex attractant as an antimicrobial agent. Chemoecology 2001, 11, 225-229. [CrossRef]

24. Schneider, C.A.; Rasband, W.S.; Eliceiri, K.W. NIH Image to ImageJ: 25 years of image analysis. Nat. Methods 2012, 9, 671-675. [CrossRef]

25. SAS Institute. SAS Stat Studio 3.8: User's Guide; SAS Institute: Cary, NC, USA, 2018.

26. SAS Institute. SAS/STAT 14.3: User's Guide; SAS Institute: Cary, NC, USA, 2017.

27. Hussein, H.M.; Zemek, R.; Habuštová, S.O.; Prenerová, E.; Adel, M.M. Laboratory evaluation of a new strain CCM 8367 of Isaria fumosorosea (syn. Paecilomyces fumosoroseus) on Spodoptera littoralis (Boisd.). Arch. Phytopathol. Plant Prot. 2013, 46, 1307-1319. [CrossRef]

28. Abbott, W.S. A method of computing the effectiveness of an insecticide. J. Econ. Entomol. 1925, 18, $265-267$. [CrossRef]

29. Šefrová, H.; Laštůvka, Z. Dispersal of the horse-chestnut leafminer, Cameraria ohridella Deschka \& Dimic, 1986, in Europe: Its course, ways and causes (Lepidoptera: Gracillariidae). Entomol. Zeitschrift 2001, 111, 194-198. 
30. Hussein, H.M.; Skoková Habuštová, O.; Půža, V.; Zemek, R. Laboratory evaluation of Isaria fumosorosea CCM 8367 and Steinernema feltiae Ustinov against immature stages of the Colorado potato beetle. PLoS ONE 2016, 11, e0152399. [CrossRef] [PubMed]

31. Zemek, R.; Prenerová, E.; Volter, L.; Awad, M.; Weyda, F.; Hussein, H.M.; Skoková Habuštová, O.; Půža, V. Non-target impacts of Isaria fumosorosea (Hypocreales: Cordycipitaceae) on natural enemies of arthropod pests. In Proceedings of the 5th International Symposium on Biological Control of Arthropods, Langkawi, Malaysia, 11-15 September 2017; Mason, P.G., Gillespie, D.R., Vincent, C., Eds.; CABI: Wallingford, UK, 2017; pp. 294-298, ISBN 978-1-78639-411-8.

32. Pekrul, S.; Grula, E.A. Mode of infection of the corn earworm (Heliothis zea) by Beauveria bassiana as revealed by scanning electron microscopy. J. Invertebr. Pathol. 1979, 34, 238-247. [CrossRef]

33. Hassan, A.E.M.; Dillon, R.J.; Charnley, A.K. Influence of accelerated germination of conidia on the pathogenicity of Metarhizium anisopliae for Manduca sexta. J. Invertebr. Pathol. 1989, 54, 277-279. [CrossRef]

34. Wang, C.; St. Leger, R.J. Developmental and transcriptional responses to host and nonhost cuticles by the specific locust pathogen Metarhizium anisopliae var. acridum. Eukaryot. Cell 2005, 4, 937-947. [CrossRef]

35. Ment, D.; Churchill, A.C.L.; Gindin, G.; Belausov, E.; Glazer, I.; Rehner, S.A.; Rot, A.; Donzelli, B.G.G.; Samish, M. Resistant ticks inhibit Metarhizium infection prior to haemocoel invasion by reducing fungal viability on the cuticle surface: Metarhizium-tick interactions and host resistance. Environ. Microbiol. 2012, 14, 1570-1583. [CrossRef]

36. Sawada, M.; Sano, T.; Hanakawa, K.; Sirasoonthorn, P.; Oi, T.; Miura, K. Benzoquinone synthesis-related genes of Tribolium castaneum confer the robust antifungal host defense to the adult beetles through the inhibition of conidial germination on the body surface. J. Invertebr. Pathol. 2020, 169, 107298. [CrossRef] [PubMed]

37. Grizanova, E.V.; Coates, C.J.; Dubovskiy, I.M.; Butt, T.M. Metarhizium brunneum infection dynamics differ at the cuticle interface of susceptible and tolerant morphs of Galleria mellonella. Virulence 2019, 10, 999-1012. [CrossRef] [PubMed]

38. Vega, F.E.; Dowd, P.F.; McGuire, M.R.; Jackson, M.A.; Nelsen, T.C. In-vitro effects of secondary plant compounds on germination of blastospores of the entomopathogenic fungus Paecilomyces fumosoroseus (Deuteromycotina: Hyphomycetes). J. Invertebr. Pathol. 1997, 70, 209-213. [CrossRef] [PubMed]

39. Leuthardt, F.L.G.; Glauser, G.; Baur, B. Composition of alkaloids in different box tree varieties and their uptake by the box tree moth Cydalima perspectalis. Chemoecology 2013, 23, 203-212. [CrossRef]

40. Kiran, B.; Olgun, C.; Verep, D.; Gur, M.; Guney, K.; Altuner, E.M.; Ates, S. Determination of flavonoids and antimicrobial Behavior of non-wood forest product extracts. Fresenius Environ. Bull. 2018, 27, 2499-2504.

41. Zazharskyi, V.V.; Davydenko, P.O.; Kulishenko, O.M.; Borovik, I.V.; Brygadyrenko, V.V. Antimicrobial activity of 50 plant extracts. Biosyst. Divers. 2019, 27, 163-169. [CrossRef]

Publisher's Note: MDPI stays neutral with regard to jurisdictional claims in published maps and institutional affiliations.

(C) 2020 by the authors. Licensee MDPI, Basel, Switzerland. This article is an open access article distributed under the terms and conditions of the Creative Commons Attribution (CC BY) license (http://creativecommons.org/licenses/by/4.0/). 